\title{
Analysis of inventory management of slow-moving spare parts by using ABC techniques and EOQ model-a case study
}

\author{
Walid Emar' ${ }^{1}$, Zakaria Anas Al-Omari², Sami Alharbi ${ }^{3}$ \\ ${ }^{1,2}$ Renewable Energy Engineering Department, Faculty of Engineering, Isra University, Amman, Jordan \\ ${ }^{3}$ Engeering Projects Management, Faculty of Engineering, Isra University, Amman Jordan
}

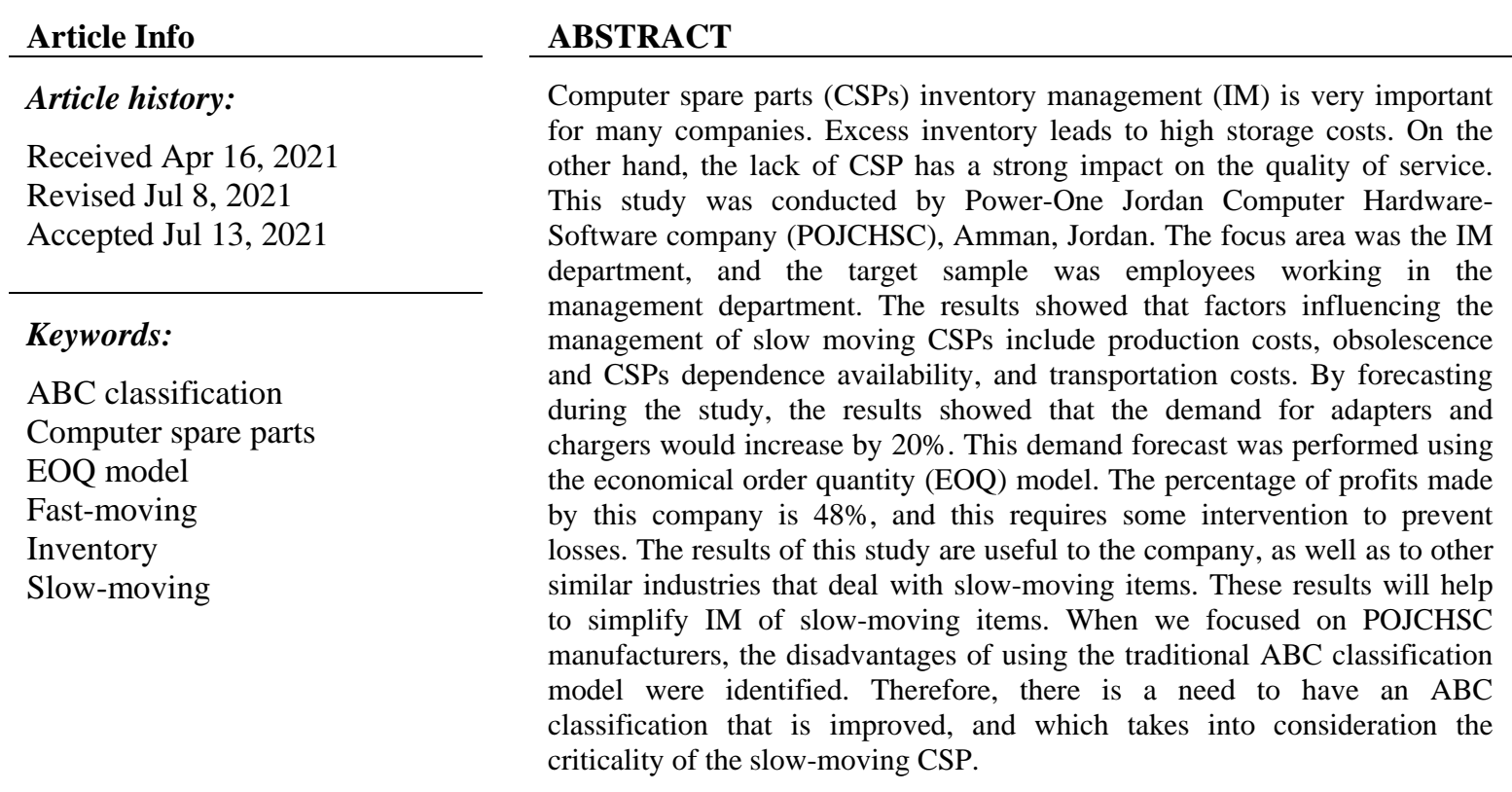

This is an open access article under the $\underline{C C B Y-S A}$ license.

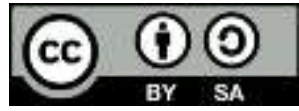

Corresponding Author:

Zakaria Al-Omari

Renewable Energy Engineering Departement, Faculty of Engineering

Isra University

Amman, Jordan

Email: zakaria.alomari@iu.edu.jo

\section{INTRODUCTION}

Each business organization usually keeps inventories to monitor the flow of their goods in and out of the organization. The management of inventories depends on whether the items being sold are slowmoving or fast-moving. However, the management of inventories for the slow-moving items can be very challenging. Spare parts for slow-moving inventories are neither intermediate nor final products which a customer may directly purchase. In addition, policies governing such kinds of inventories vary from those governing the work-in-progress (WIP) together with other inventories. The control of an inventory plays a very critical role in the spanning of businesses [1]-[3]. The lack of effective methods in inventory control leads to the suffering of the supply, and it makes it challenging to adequately meet the needs of their customers and ultimately, the bottom line of the company will not give a reflection of these inadequacies. However, by choosing the correct method for the control of inventory as well as the development of effective policies for ensuring that there is a follow up of the accuracy of controlling methods of inventory [4]-[7]. 
Item inventories is consistone of the most important components of the current assets of most companies. Mostly, the approximate average percentage of current assets is within public limited companies around the world. Due to the sheer volume of inventories held by business or corporate organizations, a large amount of money may be allocated towards them. Hence, it is absolutely essential to ensure that inventories are managed effectively and efficiently to avoid making unnecessary investments. Any company that ignores the issue of inventory management only risks the long-term profitability it will have and may ultimately fail. There is a possibility that the company will be able to reduce its inventory level considerably, for example, from 10 to $20 \%$ without affecting having any negative impact on sales or production. This can be done using simple inventory techniques in planning and monitoring inventories. Reducing "excessive" inventory is accompanied by a positive effect on the profitability of the company [8].

To assist companies in selecting or developing methodologies that fit the business requirements, Aas companies grow, they tend to accumulate spare parts for their operations that are able to restricts huge amounts of cash as well as incur large costs due to duplication, write-offs and insurance cost as well. Firms often ignore opportunities to make optimal use of their inventories, and in some cases, this is due to the a fear that the business will be in danger in the event that spare parts are not available and while at other times it is due to errors in operations, software, or evenand accounting practices [7]-[9].

Often, slow-moving inventory is not given a high priority by seen as a simple goal of people doing an inventory audit. Instead of having a structured review process, most people aim for slow-moving inventory in a way that consists of a silver bullet aimed at improving inventory. Usually, this is according to the belief that slow quality is evidence that customers do not demand such items. In my opinion, there may be a need for this type of cargo; However, supply issues may indicate that it requires it to be kept in stock. Spare parts are also referred to as spare parts that can be defined as interchangeable parts that are kept in stock and whose purpose is to replace or repair the parts of a particular machine that have failed in their operations [4]-[6], [10].

Inventory management can be defined as the continuous process consisting of planning, organizing, and controlling inventory and which aims to reduce the investment made within inventory as demand and supply are balanced. In particular, this process entails overseeing the supply and warehousing as well as the accessibility of items, as well as to ensure adequate supplies minus oversupply [6]-[8].

Some of the key factors in managing slow-moving spare parts inventories. One such factor is that there is a rise in customer expectations regarding product quality as well as services associated with slow moving spare parts. Due to this factor, customers fail to make repairs to their machines that require replacement parts, which exacerbates negative customer perceptions of spare parts. The second factor is that some items, namely spare parts, have a high demand due to their rate of growth in wear, however, most of them have intermittent demand. The last major factor that was revealed was the increased complexity of the products and reduced their life cycles, which increased the level of active codes as well as the risk of obsolescence [10]-[12].

In the analysis of spare parts storage, their specific, often unpredictable nature is an objective problem. Some spare parts require a high standard, and some are very small (from one to several years), which greatly complicates the anticipation and prediction of the level of significance of their replacement. When managing spare parts inventory, one must know the answers to several important questions [8], [9]:

- To keep or not keep spare parts in stock?

- What is the optimal number of parts to be kept in stock?

- When to request a new order?

- What is the optimum quantity to order only to satisfy external customers or the internal requirements of some items? Thus, the question shouldn't just be to place or not to place an order. "How many items or orders?" Instead, it should be: "What is the appropriate quantity to order under company conditions?

This work attempts to answer the above questions; by addressing the issue of how to make the inventory classification and volume order management to make a major difference in cost management and effectiveness. There are different types of spare parts inventory management techniques and models that can be used to more effectively manage spare parts inventory. This paper focuses on implementing $\mathrm{ABC}$ analysis using the economical order quantity (EOQ) model using software technology. ABC analysis always stands for best control analysis as the items of inventory are classified into three classes, namely: A, B and C. Items in the inventory class are closely controlled as a constant turnover is controlled over time and future demand can be easily anticipated. Items in Category $\mathrm{Y}$ are characterized by variation of demand to a certain extent depending on factors of season, product life cycle, competitor's business, or economic situations. A classic well-known formula for deciding how much inventory a firm can require at any point in time and when they should place an order, an EOQ can be used successfully [13].

The purpose of this paper, therefore, is to adopt the strategy of using the EOQ model with XYZ technology described in [13] for ABC technology. This will facilitate inventory strategy selection and 
inventory management for parts within manufacturing and sales companies or suppliers. The model aims to reduce stock holding and bearer costs to improve the efficiency and effectiveness of organizations. This is achieved through:

- Conducting an ABC analysis to access the classification of materials to minimize inventory.

- Conducting the EOQ model and Recalling the results obtained in [13] to manage inventory costs per order.

- Building a questionnaire to assess current inventory management.

- Building a computerized inventory management system for inventory control in general.

The results of this paper show that the total cost of holding and carrying is significantly reduced while service efficiency and realization are improved as required. And most satisfyingly, the proposed technology is simple and straightforward enough to be implemented by company managers which increases the potential for adoption in other or similar industries.

\section{INVENTORY MANAGEMENT METHODS AND TECHNIQUES}

To effectively manage the company's inventories, there is a need to search for answers to the following questions: The amount required and when should this order be made. The first question of the amount to be requested relates to the problem involved in determining the method and method appropriate for a given level of inventories. On the other hand, the second question of when the request should be made arises due to uncertainty and is a problem in knowing the point of rearrangement [13]. Choosing the right inventory management techniques for doing business is not easy. The faster the business changes, the more difficult it is to control inventory. In this section, some techniques and the best methods of inventory management are explained.

\subsection{Economic order quantity}

The EOQ model is one of the oldest techniques used in inventory management from an economic point of view. Because it determines the optimal quantity that the company must be store in order to reduce inventory costs related to holding, ordering and shortage costs. This is an important method for companies with small assets which need to make correct order.

Depending on the EOQ, inventory of computer spare parts (CSPs) costs can be divided into two broad categories: ordering and receiving cost. The first is the cost of the purchase. Each order has a fixed cost for shipping parts, handling orders and delivering parts from stock. The second type, maintenance cost, is the cost that comes from organizing, arranging and maintaining the inventory. When demand and demand increase, all fixed costs are divided according to the number of pieces required. Although the cost per second is determined per unit, it increases over time based on the parts in stock. Therefore, an increase in the ordering quantity means that the parts will remain in stock for a longer period, which means that the cost of maintaining the inventory will also increase [13]-[15].

\subsection{Assumption of the basic EOQ model}

There are some assumptions required to maintain the basic EOQ model (assume that the unit of time is one year for ease and clarity):

- The demand must be decisive and occur at a steady rate without change.

- If an order is incurred of any volume (for example, Q units), ordering and setting cost is also incurred.

- Waiting time for each request should be zero.

- The deficit does not exist.

- You can specify the cost per unit, year of reserved inventory (h).

Figure 1 shows inventory variations for different values of $Q$ assuming a constant and continuous demand of a certain number of units per month. The average inventory level given by (1) is estimated just to avoid complete inventory depletion. This helps to trigger an action to replenish that inventory stock. It is normally calculated as the forecast usage during the replenishment lead time plus safety stock. In the EOQ model, there is no time lag between the ordering process and the procuring process of materials. A reorder point is a technique to determine when to order; it does not address how much to order when an order is made [16].

$$
\text { Average inventory level }=Q / 2
$$

\subsection{ABC classification}

ABC inventory analysis is a popular technique used in inventory management by business organizations. It is a well-known approach that can also be called always better management. The process involved in $\mathrm{ABC}$ classification consists of various objects such as finished goods, items in stock, or even customers in three groups. This makes the ABC curriculum a classification-based system with similarities to 
Pareto analysis as shown in Figure 2 [17]-[21]. This method devide the inventory according to these techniques, where Class A represent a fluctuating percentage between $(70 \%-80 \%)$ of consumption. (15$25 \%$ ) of the "B" items represent (5-10\%) of the total consumption and the remaining portion, ie $(65-75 \%)$ for the " $C$ " items, and it represents (5-10\%) of the consumption. Article's "A" has a high value, "C" articles have a low value, while "A" articles are the intermediate value of classes A, B, and C. All of these categories of articles contain a store / buy policy, as category "A" articles are reviewed more critically, and in category "B" articles there is less review and less revision in category " $\mathrm{C}$ " articles [14]-[21].

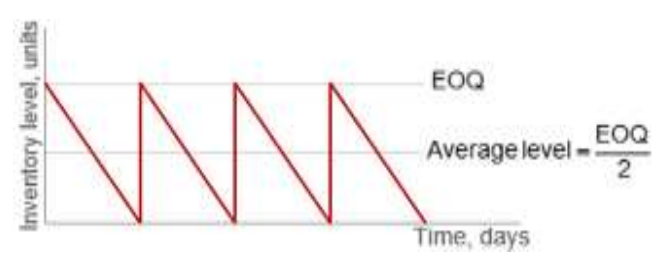

Figure 1. Time relationship with quantity in EOQ

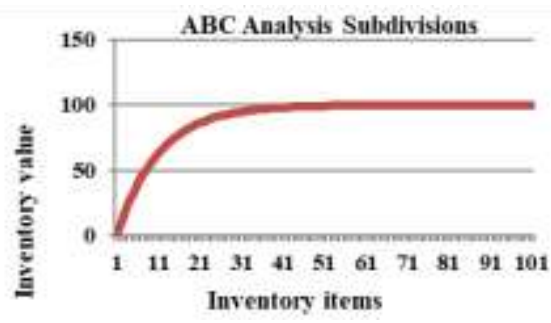

Figure 2. ABC analysis subdivisions

\section{METHODOLOGY AND OBJECTIVES}

This study is categorized into a plurality of layers, where these layers represent a various set of approaches, methods, strategies and data gathering.

\subsection{Study site}

The research was conducted at Power-One Jordan Computer Hardware and Software Company, computer parts (CPs) industries located in Jordan. Specifically, the inventory management and target sample department were the personnel working in this stock management department.

\section{3 .2. Approach, scope, and strategy}

Several different techniques have been adopted to assist this study in achieving its objectives. Different techniques and methods were used at different stages of the study. These methods were interconnected, and all of them were intended to find the effect of inventory management on a slow-moving component of CPs. For example, data were collected at the start of the study to ensure there was sufficient time to analyze and prepare well in graphs and figures for presentation. Besides, various materials were used to ensure the data were properly collected. The interviews are well structured and simple on plain, clean paper. The questions were formulated using simple language that was easy to understand which prevented the misleading data being collected. A laptop computer was used to record data in a Microsoft Excel spreadsheet. Other information was recorded in the notebooks to supplement the recorded information. All industry information about slow-moving IT spare parts inventory management was considered significant and collected for further evaluation.

Data were analyzed using a frequency distribution table in Microsoft Excel, as well as the classic ABC model. ABC stock analysis was used to subdivide the study area to refine the research. This is because it is a method of classifying inventory that involves dividing items into three classes (A, B, and $\mathrm{C}$ ). These subcategories are: A being the most valuable items; B is the inter class item, with a medium consumption value; $\mathrm{C}$ being the least valuable one. This method was aimed to draw attention to the critical few items in the first class (A-items) and not on the trivial many items in the third class (C-items) [22], [23]. After data analysis, the results were used to formulate pie figures, bar graphs, and line graphs. This study was limited to the CSPs industry at the department of inventory management and the target sample were only the staff working at this inventory management department. Both the subordinates and managers of this department were included.

\section{DATA COLLECTION AND ANALYSIS}

Data collection and analysis is a very vital part of the project as it provides the backbone for project work. In this section, the work procedures performed, i.e. data collection or study results will be discussed and presented, and finally, the data collected will be analyzed. Also, this section contains the hypothesis of the study. The tables were used to present the data collected through the study. 


\subsection{Data collection}

The study site for this research is the CPs industry in the inventory management department, while the target sample will be the employees working in this inventory management department. The research was both quantitative and qualitative. The target sample interviewed during the study was a total of 100 employees from the CPs industry. The research strategy for this study topic is to design a case study. The items or parts sold by industry were then listed and then classified using the $\mathrm{ABC}$ model. The results are also presented using tables. Table 1 indicates the cost of the CPs involved in this study.

Table 1. Average prices of (CSP) sold by the industry

\begin{tabular}{|c|c|c|c|c|c|}
\hline \# & Item & Prices (US \$) & $\#$ & Item & Prices (US \$) \\
\hline \multicolumn{3}{|c|}{ Class A items } & \multicolumn{3}{|c|}{ Class B Items } \\
\hline 1. & LCD Screen & 60 & & Battery & 2.5 \\
\hline 2. & Adapter and chargers & 30 & 2. & Remote & 200 \\
\hline 3. & Internal hard drive & 50 & & Floppy drive & \\
\hline 4. & Mouse & 4 & \multicolumn{3}{|c|}{ Class C Items } \\
\hline 5. & The central processing unit (CPU) Monitor & 70 & 1. & Universal serial bus & 140 \\
\hline 6. & Memory & 20 & 2. & External hard drive & 45 \\
\hline 7. & Fuser unit & 43 & & & \\
\hline 8. & Keyboard & & & & \\
\hline
\end{tabular}

\subsection{Factors affecting the inventory mangement of CSP}

From the research study carried out, the following are the factors that were found out to affect inventory management of CSP [24]-[26]:

- The cost of transport is incurred during the repair period. This is because some repair may need to be carried to the repairing center to be repaired. So, transportation costs might be put into consideration.

- Maintenance policies in determining the demand for CSP. Critical CSP need to be replaced based on a set schedule as opposed to some spare parts which are replaced when a machine shuts down.

- Dependence of some of the parts failure. Generally, the dependence relation is unavailable.

- Problems are caused by some of the CSP that are obsolete.

- Availability of computer technicians who can help in repairing computers through replacements of the parts that are not in good condition. When these technicians are available, computer owners will prefer purchasing spare parts for repair instead of dealing with the entire computer by disposing of it.

\subsection{Classification of the computer parts}

The CSP investigated in this study research were classified using the classical $\mathrm{ABC}$ model. This is the most common and simple way used in classifying slow-moving items to have easiness in their inventory management. This classification was done according to the guidelines given by Kennedy et al., (2012), who argue that items should be classified based on their level of significance. In this model, CSP were categorized into three classes named [27], [28]: i) Class A items-for very important item; ii) Class B items-for important items; iii) Class $\mathrm{C}$ items-for the least important items.

\subsection{Questionnaire design}

The study focused on all employees working in the inventory management department. The personnel who have worked in the department for more than five years were selected as they were believed to have a clear understanding of the activities taking place in the department. Likewise, I focused on inventory management only for CPs. The exclusion criteria covered employees from all other departments, as well as inventory management for all other slow-moving items in the industry. Likewise, employees who had worked in the department for less than five years were excluded. The subject sample for the study was randomly selected. This was regardless of the placement of the target sample based on the employee's position, inventory department, or CPs occupied.

\subsection{Probability sampleing and sample size determination}

Probability sampling was the strategy used in the study for sample selection. This strategy was naturally visualized from the research design flow. In this strategy, department employees were distributed equally in the likelihood to be elected. This method was used because by selecting a small random sample from the sample, the distribution of the entire sample can be easily estimated. There was no bias in sample size because this sampling strategy ensured an unknown opportunity for staff selection. Besides, the strategy allowed the calculation of the confidence level with sampling errors. Since the study wanted to investigate 
several topics and not a specific topic, a simple random sampling method was adopted to aid in selecting the target group for the study. The method guaranteed accuracy in the following analysis, as first evaluations were not biased and were the basis for subsequent evaluations. With this strategy, a clear representative sample of the sample was obtained. This method was appropriate and could provide any amount of data required in the study. This is because other underlying data are needed to address any gaps that may arise. According to Dunsmuir and Snyder [28], the formula that was used to calculate the sample size is the following [23], [24]:

$$
n=\frac{Z^{2} \times p \times(1-p)}{C^{2}}
$$

where $n$ : sample size; $Z$ : confidence level, can be in percentage or decimal or population size; $p$ : It is the percentage pinking a choice, expressed as a decimal; e: confidence interval (C.I) expressed as a decimal.

\subsection{Data analysis and results from the questionnaire}

Table 2 indicates the responses given during the interviews with workers at the CSP industry. These responses were based on the views of the interviewed by using questionnaires. It indicates the responses of the staff interviewed of ways how the slowness in the moving of CPs can be controlled: A-respondents who strongly agree; B-respondents who just agree; C-respondents who just disagree; D-respondents who strongly disagree. From the data collected during the study, Table 2 and Figure 3 show that $67 \%$ of all respondents strongly support that buyer can prevent slow sales of CPs through repeated purchases only. Only $13 \%$ supported this statement. On the other hand, $11 \%$ simply disagreed that buyers do not influence CPs to be slow-moving items in the industry and $9 \%$ of the survey strongly disagreed with this idea. A higher percentage of respondents believe that buyers can help prevent slow-moving elements in the industry.

On the other hand, $16 \%$ of the total number of respondents strongly agreed with the idea of preventing slow inventory management of CPs which they argued that workers in the slow-moving parts industry should help control the inventory of slow-moving parts. The percentage of respondents who just agreed with this statement was $23 \%$, while the highest percentage, $47 \%$, simply disagreed with this argument. The percentage that strongly rejected was $14 \%$. This is illustrated in Figure 4.

Table 2. Prevention of slow-moving inventories for CSP

\begin{tabular}{|c|c|}
\hline Prevention of slow-moving CSPs & A $\quad$ B $\quad$ C $\quad$ D \\
\hline It is difficult to prevent the inventory of CSPs from being slow-moving items & 15381235 \\
\hline CSPs are obsolete items in nature & 044254 \\
\hline It's only buyers who influence the slowness of the inventory of slow-moving computers spare parts & 6713119 \\
\hline Manufacture of less durable spare parts makes their inventory to be fast moving & 32302919 \\
\hline Prices of the computers spare parts influences their rate in and out flow of the industry & 15194125 \\
\hline Production cost is the key factor influencing the slowness of CSPs in industries. & 4233196 \\
\hline
\end{tabular}

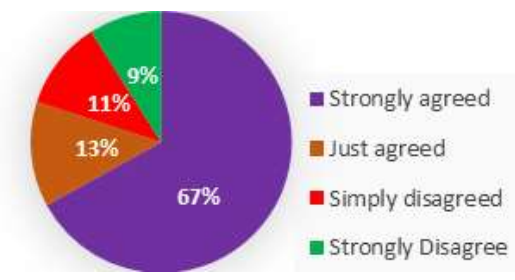

Figure 3. Responses of the staff to claim: it is only buyers who influence the slowness of the inventory of slow-moving computers spare parts

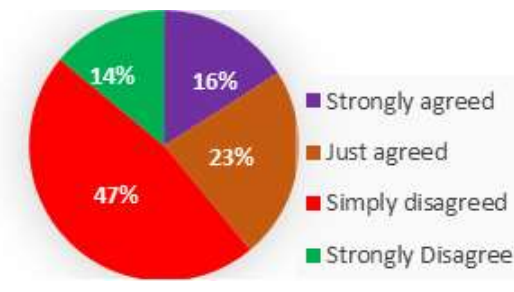

Figure 4. Responses of the staff to the claim: the staff at the slow-moving spare parts industry must help in control the inventory of slow-moving spare parts

The claim about CPs prices affecting their rate of entry and exit from the flow of industry was also investigated during the study, as shown in Figure 5. The last factor studied to influence the slow-selling of CPs was the cost of production. Figure 6 shows that $42 \%$, the highest percentage of respondents, strongly support the idea that reducing the cost of a CPs product will help manage their inventories by increasing sales. The percentage who just agreed with this idea was 33\%, while $19 \%$ disagreed with it. The percentage 
of respondents who strongly disagreed with this idea was only $6 \%$. The majority of respondents supported this idea, while only $28 \%$ of the total sample agreed with it.

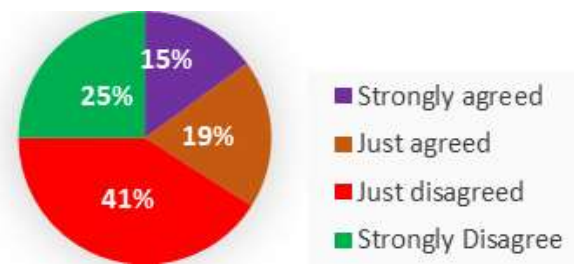

Figure 5. Responses of the staff to the claim, that Prices of the computers' spare parts influence their rate in and out the flow of the industry

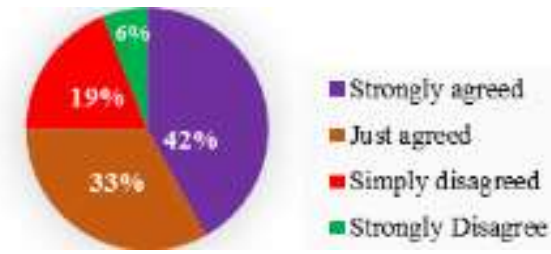

Figure 6. Responses of the staff to the claim, that Prices of the computers' spare parts influence their rate in and out the flow of the industry

\subsection{Prevention of slow-moving inventories for CSP}

From Table 3 and Figure 7 we see that the majority of respondents agreed with the idea that inventory management teams in the CPs industry were responsible for the slow-moving elements in that company. While 49\% strongly agreed, $39 \%$ simply agreed. Only $1 \%$ disagreed with this factor, while $11 \%$ strongly opposed it. The difference in the percentage of respondents who strongly agreed and who strongly disagreed was 38\%, while the percentage between respondents who only agreed and those who simply disagreed was also $38 \%$. This is a big difference. Nearly $37 \%$ of the respondents fully agreed that consumer behavior is a factor affecting inventory management of slow-moving items, and $29 \%$ of this sample agreed. The percentage of respondents who simply did not agree with this factor was $29 \%$, and $15 \%$ of the total study sample strongly opposed it. Thus, the highest percentage supports that inventory management is a factor affecting slowness in sales of CPs. A total of 54\% of the entire sample strongly agreed that the quality and durability of CPs impact inventory management. $28 \%$ simply agreed with this factor, while only $7 \%$ did not, and only $4 \%$ strongly agreed that these factors affect CPs inventory management as slow-moving items in the industry.

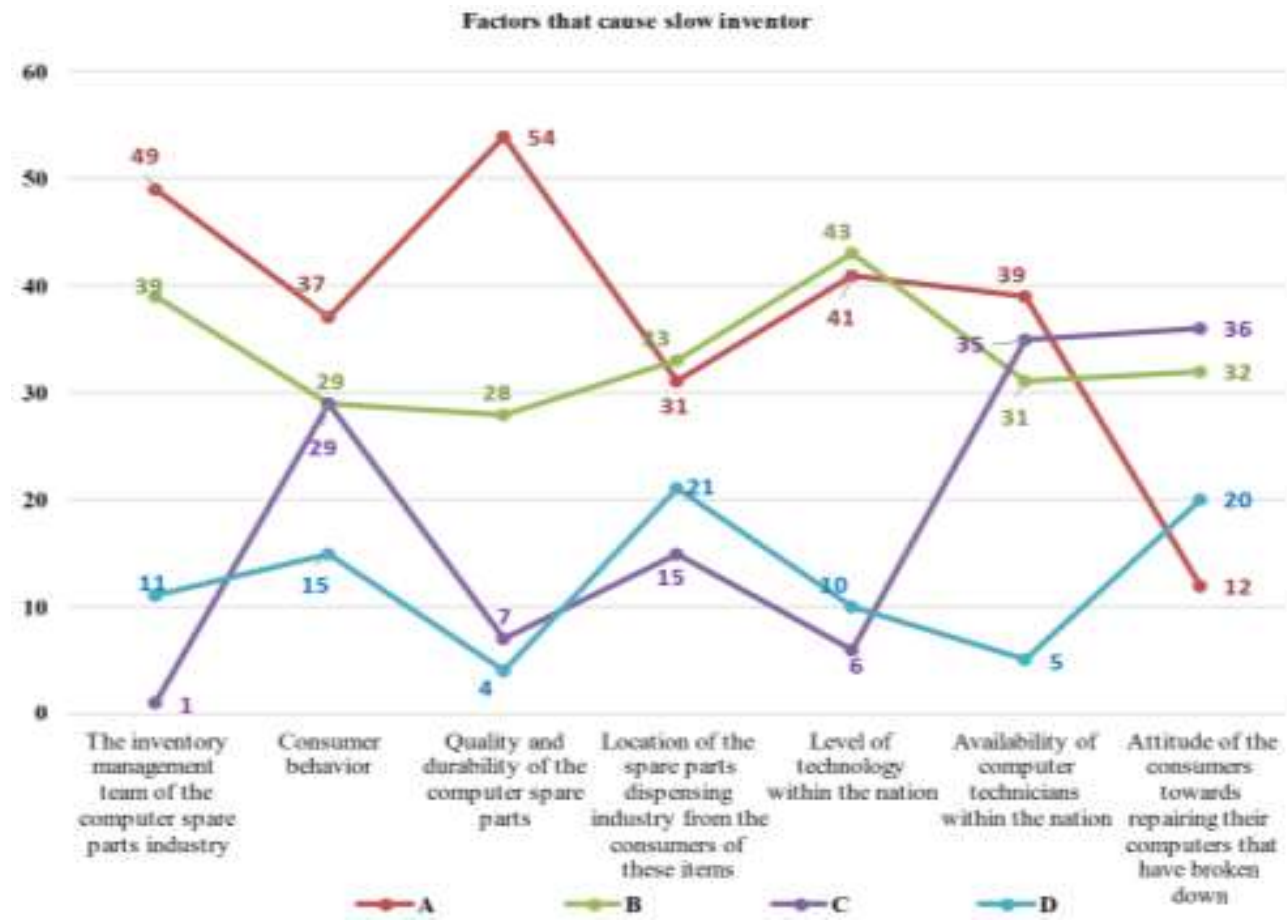

Figure 7. Factors that influence slow inventory at the CSPs industries 
Table 3. Factors that influence slow inventory at the CSPs industries

\begin{tabular}{|c|c|c|c|c|}
\hline Factors affecting inventory management of slow-moving CSPs & A & B & $\mathrm{C}$ & D \\
\hline The inventory management team of the CSPs industry & 49 & 39 & 1 & 11 \\
\hline Consumer behavior & 37 & 29 & 29 & 15 \\
\hline Quality and durability of the CSPs & 54 & 28 & 7 & 4 \\
\hline Location of the spare parts dispensing industry from the consumers of these items & 31 & 33 & 15 & 21 \\
\hline Level of technology within the nation & 41 & 43 & 6 & 10 \\
\hline Availability of computer technicians within the nation & 39 & 31 & 35 & 5 \\
\hline Attitude of the consumers towards repairing their computers that have broken down & 12 & 32 & 36 & 20 \\
\hline
\end{tabular}

The location of the industry that produces consumer CPs has also been verified as a factor affecting inventory management of slow-moving CPs. $31 \%$ of the respondents strongly supported this statement and simply $33 \%$ of the total interviewed sample agreed with it. On the other hand, only $15 \%$ of respondents simply do not agree about the deal and $21 \%$ of respondents strongly disagreed with the industry location factor as a contributing factor to the decline in sales of CSPs.

The difference between the total number of respondents interviewed during the study who agreed with the industry's position as a factor affecting inventory management of slow-moving CPs and the total number of those who opposed was $28 \%$. The difference in the percentage between respondents who strongly agreed with this factor and those who strongly disagreed with this factor was only $10 \%$, while the difference in percentage between respondents who simply agreed and those who simply disagree was $18 \%$.

Another factor that was considered in this study to influence the slowdown in the number of sales of CPs in the industry is the level of technology within the country in which the industry is located. Figure 8 shows that $41 \%$ of the sample respondents strongly agreed that this factor is related to the decrease in the number of sales of spare parts. $43 \%$ of those surveyed just agreed with this factor. On the other hand, the percentage of respondents who simply did not agree with this factor was $6 \%$, while the percentage who strongly disagreed with this factor was $10 \%$. Therefore, the majority of respondents supported the idea of looking at the level of technology as a factor that contributed to the slow movement of CPs, and this percentage was $84 \%$. Therefore, technology affects inventory management of slow-moving CPs because it determines the number of computers purchased within that particular country.

Additionally, the study also looked at the availability of computer technicians within the country as another factor contributing to the slow sales of CPs by the industry that produces them. The availability of computer technicians means that if a part breaks down, it can be repaired, and thus the sale of CPs will increase. About $39 \%$ strongly agreed with this factor, while $31 \%$ of those surveyed agreed fairly. On the other hand, only $35 \%$ of the respondents agreed with this factor, while only $5 \%$ fully agreed with this factor. So, a percentage is higher if it is more than $50 \%$ in favor of this factor. The final factor was the consumers' attitude towards fixing broken computers shown in Figure 9.

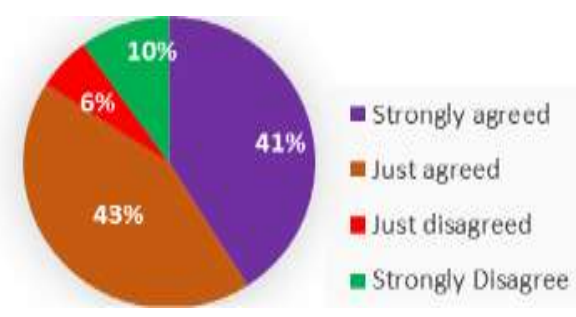

Figure 8. Staff responses concerning technology level as factor affecting slowness in the inventories of CSPs

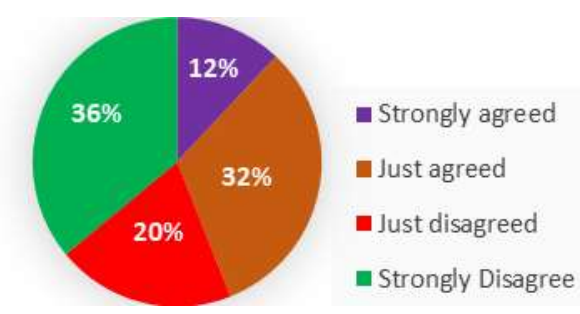

Figure 9. Attitude of the consumers towards repairing their computers that have broken down

\subsection{Relationship between inventory policy and slow-moving CSP}

The results of the study in Table 4 and Figure 10 indicated different attitudes of the respondents towards the idea of imposing an inventory policy as a means of controlling the inventory management of the slow-moving CPs in the industry. The allegation investigated is that if the implementation of the inventory policy in the aftermarket takes too long and thus should be discouraged. The difference between respondents who strongly agreed with and those who strongly disagreed with this factor was $56 \%$, which is a very large difference, while the difference between respondents who simply agreed and those who simply disagreed was 43\%. The difference in percentage between the respondents who agreed and those who disagreed with the 
implementation of the inventory policy was very high, about $99 \%$, indicating that almost all respondents were in favor of this idea.

Figure 11 shows that $51 \%$ of the total number of respondents strongly support the claim that inventory policy in the industry affects prices and sales of slow-moving CPs and only $45 \%$ just agree. On the other hand, only $4 \%$ of the respondents strongly disagreed with this statement and none of them just disagreed with this idea. The difference between the total number of agreeing responders and disagreeing respondents was $92 \%$, which is a very huge difference. The difference between respondents who strongly agreed and those who strongly disagreed with the effect of stock policy on CPs prices was $47 \%$, while the differences between respondents who only agreed and those who simply did not agree during the interview were $45 \%$.

Table 4. Respondents' answers to inventory policy and slow-moving parts relationship

\begin{tabular}{|c|c|}
\hline Respondents' answers to inventory policy and slow-moving parts & A $\quad$ B $\quad$ C $\quad$ D \\
\hline Inventory policy has a great impact on the management of slow-moving CSPs & 12243723 \\
\hline Implementation of inventory policy makes the slow-moving CSPs obsolete & $5643 \quad 1 \quad 0$ \\
\hline $\begin{array}{l}\text { Implementation of inventory policy at the spare parts industy is time-consuming } \\
\text { and hence ought to be discouraged }\end{array}$ & $\begin{array}{llll}23 & 17 & 29 & 31\end{array}$ \\
\hline $\begin{array}{l}\text { Implementation of inventory policy is expensive since it requires some special skills and training } \\
\text { besides being time-consuming }\end{array}$ & 49441 \\
\hline Inventory policy affects prices and the sales of slow-moving CSPs & 51450 \\
\hline $\begin{array}{l}\text { Inventory policy would work at its best level when it is used in association with } \\
\text { motivation towards the inventory management staff }\end{array}$ & $\begin{array}{llll}43 & 12 & 18 & 27\end{array}$ \\
\hline $\begin{array}{l}\text { Modification of the CSPs can help in promoting the implementation of inventory policy } \\
\text { in industries selling slow-moving CSPs }\end{array}$ & 23123827 \\
\hline $\begin{array}{l}\text { Some staff at the inventory management department know the importance of implementing } \\
\text { inventory policy for the items that are slow-moving at the industry }\end{array}$ & 43221718 \\
\hline he industry management should be responsible for setting up inventory policy of the slow-1 & \\
\hline
\end{tabular}

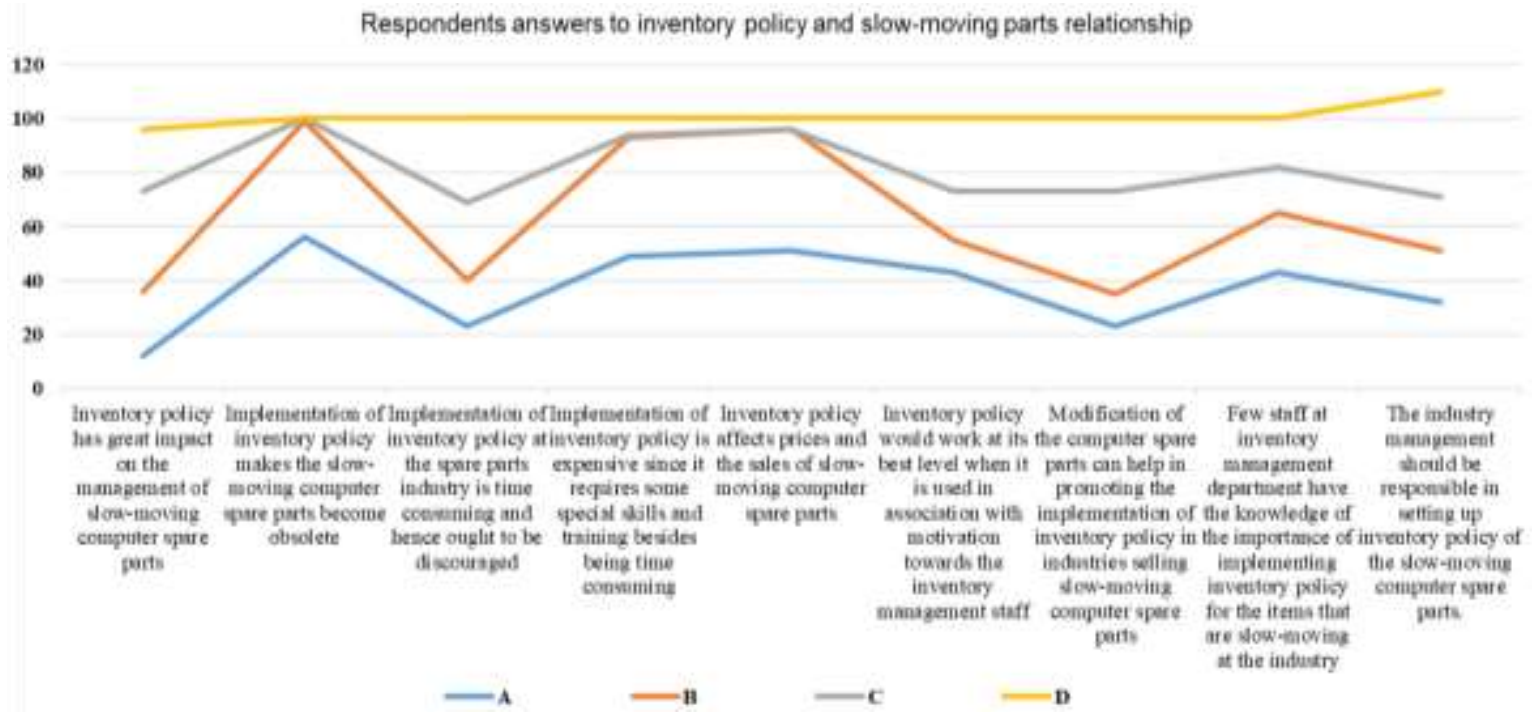

Figure 10. Respondent answers to inventory policy and slow-moving parts relationship

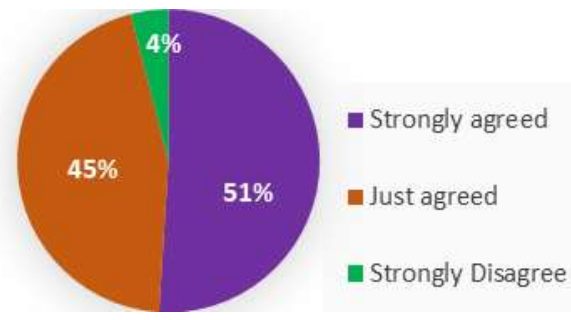

Figure 11. Respondent answers toinventory policy and slow-moving parts relationship 
Figure 12 shows that $49 \%$ of all respondents strongly agreed that implementing the inventory policy is costly, as it requires some special skills and training in addition to being a waste of time. On the other hand, $44 \%$ just agreed with this statement. Only a few of the respondents disagreed with this statement with only $1 \%$ disagreeing and $6 \%$ strongly opposing this statement. The $86 \%$ ratio makes the difference between the total number of respondents who support and the total number of those who do not support very high.

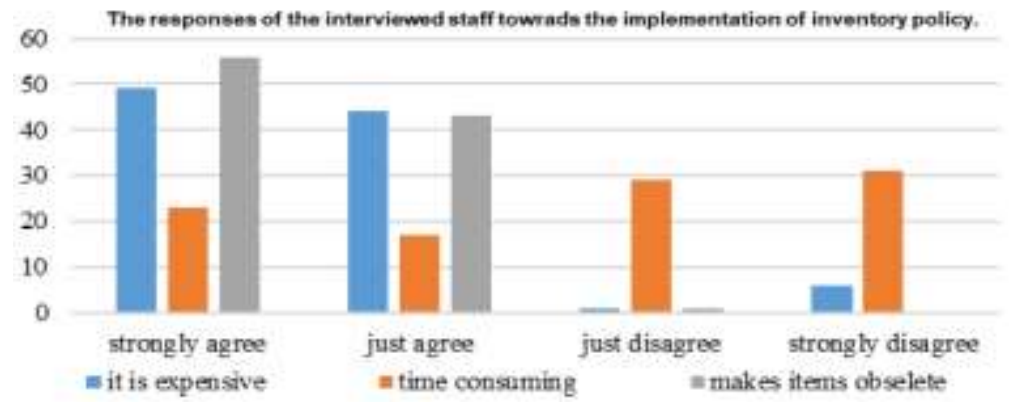

Figure 12. The responses of the interviewed staff towards the implementation of inventory policy

\section{CONCLUSIONS}

Based on the result obtained from this study, XYZ-EOQ classification model is confirmed to be a suitable model for the classification of items to slow-moving and fast-moving CSPs. The implementation of inventory policies plays a vital role in managing slow-moving items, such as CPs. However, this implementation requires coordination among all company workers who deal with CSPs that are slow-moving in nature. The obsolescence of some CPs is a factor that greatly affects the slow sales of them because it is a factor that occurs somewhat naturally without being affected by other external factors. The senior management team's role is to meet the inventory management challenges of slow-moving items. $65 \%$ of the total employees interviewed during the study agree with the idea that top management is an influential factor in managing the inventory of slow-moving CPs. Knowing the importance of implementing inventory policies helps in managing the inventory of slow-moving items, such as CPs, that are not well known to employees in industries that deal with slow-moving items. Therefore, this may be the reason why Jordan Computer and Software Corporation employees oppose implementing these inventory policies in the industry's stock management department. Formulating inventory policies will also help reduce the time it takes to take inventory, and thus improve inventory management of CPs sold at Power-One Jordan computer hardware and software manufacturers.

\section{REFERENCES}

[1] S. W. Lemke, "Inventory Optimization in Manufacturing Organizations", Walden University, Walden Dissertations and Doctoral Studies, 2015. [Online]. Available: https://scholarworks.waldenu.edu/cgi/viewcontent.cgi? article $=1753 \&$ context $=$ dissertations

[2] F. Bakker, T. Boehme, and D. P. Van Donk, "Identifying barriers to internal supply chain integration using systems thinking," $4^{\text {th }}$ Production and Operations Management World Conference, Amsterdam, The Netherlands, 2012, pp. 1-10. [Online]. Available: http://ro.uow.edu.au/commpapers/2778

[3] A. Brüggen, R. Krishnan, and K. L. Sedatole, "Drivers and consequences of short term production decisions: Evidence from the auto industry," Contemporary Accounting Research, vol 28, no. 1, pp. 83-123, 2011, doi: 10.1111/j.1911-3846.2010.01042.x.

[4] J. Ashayeri, R. M. J. Heuts, A. Jansen, and B. Szczerba, "Inventory management of repairable service parts for personal computers: A case study", International Journal of Operations \& Production Management, vol. 16, no. 12, pp. 74-97, December 1996, doi: 10.1108/01443579610151760.

[5] G. J. Bailey and Marilyn M. Helms, "MRO inventory reduction - challenges and management: a case study of the Tennessee Valley Authority," Production Planning and Control, vol. 18, no. 3, pp. 261-270, 2007, doi: 10.1080/09537280601127351.

[6] R. Bauer, N. Guenster and R. Otten, "Empirical Evidence on Corporate Governance in Europe: The Effect on Stock Returns, Firm Value, and Performance," Journal of Asset Management, vol. 5, pp. 91-104, 2004, doi: 10.1057/PALGRAVE.JAM.2240131.

[7] D. C. Bose, "Inventory management," PHI Learning Pvt. Ltd., 2011. 
[8] S. P. Sarmah and U. C., Moharana, "Multi-criteria classification of spare parts inventories-a web based approach," Journal of Quality in Maintenance Engineering, vol. 21, no. 4, pp. 456-477, 2015, doi:10.1108/JQME-04-2012-0017.

[9] J. Gu, G. Zhang, and K. Li, "Efficient aircraft spare parts inventory management under demand uncertainty," Journal of Air Transport Management, vol. 42, pp. 101-109, 2015, doi: 10.1016/j.jairtraman.2014.09.006.

[10] M. A. Cohen and H. L. Lee, "Out of touch with customer needs: spare parts and after sales service," Sloan Management Review, vol. 31, no. 2, pp. 55-66, 1990.

[11] C. M. Durugbo, "After-sales services and aftermarket support: a systematic review, theory and future research directions," International Journal of Production Research, vol. 58, no. 3, pp. 1-36, 2019, doi: 10.1080/00207543.2019.1693655.

[12] W. AL-Dulaime and W. M. Emar, "Analysis of Inventory Management of Laptops Spare Parts by Using XYZ Techniques and EOQ Model; A case Study," International Journal of Scientific \& Technology Research, vol. 8, no. 10, October 2019, doi: 10.6025/jes/2020/10/1/1-22.

[13] Dr. Rakesh kumar, "Economic Order Quantity Model (EOQ)," Global Journal of Finance and Economic Management, vol. 5, no.1, pp. 1-5, 2016, doi:10.22214/ijraset.2018.6049.

[14] R. Ramanathan, "ABC inventory classification with multiple-criteria using weighted linear optimization," Computers \& Operations Research, vol. 33, no. 3, pp. 695-700, 2006, doi: 10.1016/j.cor.2004.07.014.

[15] W. J. Kennedy, J. W. Patterson, and L. D. Fredendall, "An overview of recent literature on spare parts inventories", International Journal of Production Economics, vol. 76, no. 2, pp. 201-215, 2002, doi: 10.1016/S0925-5273(01)00174-8.

[16] N. J. Foss and N. L. Hallberg, "How symmetrical assumptions advance strategic management research," Strategic Management Journal, vol. 35, no. 6, pp. 903-913, June 2014, doi: 10.1002/smj.2130.

[17] R. Koch, "The 80/20 Principle: The Secret to Achieving More with Less, Nicholas Brealey Publishing Limited, 1998.

[18] V. Pareto, G.-H Bousquet, G. Busino, "Cours d'economie politique," Genève: Droz, 1964.

[19] O'Neill, S. Kathryn, "Applying the Pareto Principle to the analysis of students' errors in grammar, mechanics and style," Research in Higher Education Journal, vol. 34, May 2018.

[20] M. Braglia, A. Grassi, and Montanari, R., "Multi-attribute classification method for spare parts inventory management," Journal of Quality in Maintenance Engineering, vol. 10, no. 1, pp. 55-65, 2014, doi: 10.1108/13552510410526875.

[21] H. B. Bhandari, "Factors Affecting the Efficiency of Inventory Management of Janapriya Multiple Campus, Pokhara," Janapriya Journal of Interdisciplinary Studies, vol. 6, no. 78, 2017, doi: https://doi.org/10.3126/jjis.v6i0.19310.

[22] W. J. Kennedy, J. W. Patterson, and L. D. Fredendall, "An overview of recent literature on spare parts inventories," International Journal of production economics, vol. 76, no. 2, 21 March 2002, pp. 201-215, doi: 10.1016/S0925-5273(01)00174-8.

[23] J. Gu, G. Zhang, and K. W. Li, "Efficient aircraft spare parts inventory management under demand uncertainty," Journal of Air Transport Management, vol. 42, pp. 101-109, 2015, doi: 10.1016/j.jairtraman.2014.09.006.

[24] S. Cavalieri, M. Garetti, M. Macchi, and R. Pinto, "A decision-making framework for managing maintenance spare parts,” Production Planning \& Control, vol. 19, no. 4, pp. 379-396, June 2008, doi: 10.1080/09537280802034471.

[25] H. Ravinder and R. B. Misra, "ABC Analysis for Inventory Management: Bridging the Gap Between Research and Classroom," American Journal of Business Education, vol. 7, no. 3, pp. 257-264, 2014, doi: 10.19030/ajbe.v7i3.8635.

[26] S. A. Torabi, S. M. Hatefi, and B. S. Pay, "ABC Inventory Classification in the Presence of Both Quantitative and Qualitative Criteria," Computers \& Industrial Engineering, vol. 63, no. 2, pp. 530-537, May 2012, doi: 10.1016/j.cie.2012.04.011.

[27] B. D.Williams and T. Tokar, "A review of inventory management research in major logistics journals: Themes and future directions," The International Journal of Logistics ManagemenInternational, vol. 19, no. 2, pp. 212-232, 2008, doi: 10.1108/09574090810895960.

[28] W. T. M. Dunsmuir and R. D. Snyder, "Control of inventories with intermittent demand," European Journal of Operational Research, vol. 40, no. 1, pp. 16-21, 1989, doi: 10.1016/0377-2217(89)90267-1. 